\title{
Estimation of the probability of propulsion loss by a seagoing ship based on expert opinions
}

\author{
Alfred Brandowski, Prof. \\ Gdynia Maritime University
}

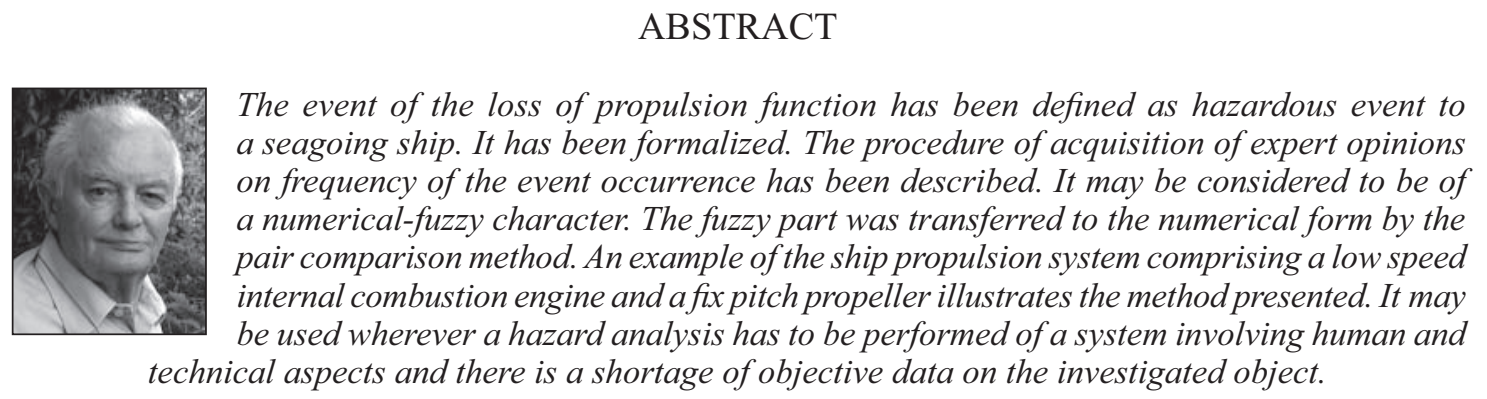

Keywords: ship, loss of propulsion, probability, estimation, expert

\section{INTRODUCTION}

Loss of the propulsion function by a ship is one of the most serious categories of hazardous events ${ }^{1}$ in shipping. In specific external conditions it may lead to a loss of ship together with people aboard. The loss of propulsive power may be an effect of the propulsion system (PS) failures or of errors committed by the crew in the system operation process. In the safety engineering language we say that the propulsion loss probability depends on the reliability of the PS and of its operators. Determination of that probability is in practice confronted with difficulties connected with shortage of data on that reliability. This pertains particularly to the cases of estimation in connection with decisions taken in the ship operation. In such cases we have to rely on subjective estimations made by persons with practical knowledge in the field of interest, i.e. experts. The experts, on the other hand, prefer to formulate their opinions in the linguistic categories, in other words in the language of fuzzy sets. The author's experience tells also that in the expert investigations it is difficult to maintain proper correlation between the system data and the system component data. The paper presents a method of the subjective estimation of propulsion loss probability by a ship, based on the numericalfuzzy expert judgements. The method is supposed to ensure that proper correlation. It is adjusted to the knowledge of experts from ships' machinery crews and to their capability of expressing that knowledge.
The method presented has been developed with an intention of using it in the decision taking procedures in risk prediction during the seagoing ship operation, in the shortage of objective reliability data situations.

\section{DEFINITION OF THE SHIP PROPULSION LOSS AS A HAZARDOUS EVENT}

The propulsion hazard is connected with the loss by the PS system of its capability of performing the assigned function, i.e. generating the driving force of a defined value and direction. It appears as an effect of a catastrophic failure ${ }^{2}$ of the PS. Such failure may cause immediate (ICF) or delayed (DCF) stoppage of a ship. In the latter case the stoppage is connected with renewal, which may be carried out at any selected moment. It is obvious that only the former case of the forced stoppage creates a risk of damage or even loss of ship - it is a hazardous event.

We will relate the probability of ICF to an arbitrary time interval determined by the analyst. For instance, it may be duration of one trip, time interval between the ship class renewal surveys or one year, as it is usually assumed in risk analyses. Such an approach is useful in the ship operation risk management process.

The ICF type failure consequences may be divided into casualties and incidents (IMO 1997). In general, the ship casualties are non-repairable at sea by means of the ship own

\footnotetext{
${ }^{1}$ Hazardous event is defined as an event bringing about damage to human beings as well as to the natural and/or technical environment.

It is also called "accident" or "initiating event".

${ }^{2}$ Catastrophic failure is defined as loss of the capability of performing by the object of its assigned function.
} 
resources and may have very serious consequences, with the ship towing at the best and the loss of ship at the worst. The problem of consequences is not the subject of this paper.

The ICF type failure frequency depends mainly on the type of PS and the ship operation mode (liner trade, tramping etc.). On the other hand, the consequences are strongly dependent on the ship size and type and the environmental conditions, first of all the water region, season, time of day, atmospheric and sea conditions. They are also dependent on the navigational decisions and on the type and fastening of cargo in the holds and on deck. In general, these are the factors connected with the type of shipping carried out and the shipping routes the ship operates on.

\section{FORMAL MODEL OF ICF EVENT}

We assume the following:

is We are interested only in the "active" phase of ship operation, when it is in the shipping traffic. We shall exclude from the model the periods of stays in ship repair yards or in other places connected with renewals of the ship equipment.

is The investigated PS system may be only in the active usage or stand-by usage state. The ICF type PS failures may occur only in the former state.

is A formal model of the ICF type PS failures is the homogeneous Poisson process (HPP). This assumption is justified by the expert elicited data, which indicate that this type of failures occur fairly often, several times a year, but their consequences in general mean only a certain loss of operation time. More serious consequences, causing longer breaks in the normal PS system operation, occur seldom. The exponential distribution of time between failures, taken place in the HPP stream model, is characteristic of a normal operation of many system classes, including also the ship systems $[1,4]$. It is appropriate in the case when the modeled object failures and the operator errors are fully random abrupt failures and not gradual failures caused by the ageing processes and/or wear of elements. This corresponds with the situation when scrupulously performed inspections and renewals prevent the latter type of failure from occurring.

is Experts are asked only about two numerical values: number of ICF type failures $\mathrm{N}(\mathrm{t})$ during time period $t=1$ year ( 8760 hours), and the time at sea percentage share $\kappa 100 \%$ during their seamanship period - this is within their capability of answering.

is The opinions on the failures of PS system components are elicited in the linguistic form.

The seagoing ship system active usage time $\mathrm{t}^{(\mathrm{a})}$ is strongly correlated with the specific ship operational state times, mainly with the "at sea" state including "sailing", "manoeuvres" and "anchoring". The following approximation may be adopted for the system, also for the PS:

$$
\mathrm{t}^{(\mathrm{a})}=\mathrm{t}^{(\mathrm{m})}=\kappa \mathrm{t}
$$

where:

$$
\begin{array}{ll}
\mathrm{t}^{(\mathrm{a})} & - \text { active usage time } \\
\mathrm{t}^{(\mathrm{m})} & - \text { time at sea } \\
\mathrm{t} & - \text { calendar time of the system observation } \\
\kappa=\mathrm{t}^{(\mathrm{m}) / \mathrm{t}} & - \text { time at sea factor }(\kappa \in\langle 0,1\rangle)
\end{array}
$$

In view of these assumptions, the ICF type PS failures may occur only in the system active usage state, i.e. for the PS system in the $\mathrm{t}^{(\mathrm{m})}$ time, although their observed yearly numbers are determined by experts in relation to the calendar time $t$.
The model ICF probability has the vector form:

$$
\mathbf{P}\left\{\mathrm{t}^{(\mathrm{a})}\right\}=\mathbf{P}\{\mathrm{\kappa} \mathrm{t}\}=\left[\frac{\left(\lambda^{(\mathrm{a})} \kappa \mathrm{t}\right)^{\mathrm{k}}}{\mathrm{k} !} \mathrm{e}^{-\lambda^{(\mathrm{a})} \mathrm{\kappa t}}: \mathrm{k}=1,2, \ldots, \mathrm{K}\right.
$$

where:

$\mathbf{P}\left\{\mathbf{t}^{(\mathrm{a})}\right\}$

- the vector of probabilities of ICF type event occurrence within time interval $\langle 0, \mathrm{t})$
$\lambda^{(a)} \approx \sum_{j=1}^{J} N_{j}(t) / \kappa_{j} t_{j}-$ intensity function of HPP (ROCOF) (and at the same time the failure rate of the exponential distributions of time between failures in that process, $[1 / \mathrm{h}]$
$\mathrm{N}_{\mathrm{j}}$
$\kappa_{\mathrm{j}}$
$t_{j} \quad-$ calendar time of observation by $j$-th expert [h]
$\mathrm{J} \quad-$ number of experts
$\mathrm{K}-\quad$ the maximum number of possible ICF type failures in the time interval $\langle 0, \mathrm{t})$
t
- the time of probability prediction.

The $\lambda^{(a)}$ formula is based on the theorem on the asymptotic behaviour of the renewal process [1]:

$$
\lim _{t \rightarrow \infty} \frac{E[N(t)]}{t}=\frac{1}{T_{0}}=\lambda
$$

where:

$\mathrm{T}_{\mathrm{o}}-$ mean time between failures.

The number of ICF type events in the $\langle 0, \mathrm{t})$ period may be $0,1,2, \ldots$ or $\mathrm{K}$ with well-defined probabilities. The maximum of these probabilities is the assumed measure of the probability of ICF type event occurrence:

$$
\mathrm{P}_{\max }\left\{\mathrm{t}^{(\mathrm{a})}\right\}=\max _{\mathrm{k} \in\{1,2, \ldots, \mathrm{K}\}} \frac{\left(\lambda^{(\mathrm{a})} \kappa \mathrm{t}\right)^{\mathrm{k}}}{\mathrm{k} !} \mathrm{e}^{-\lambda^{(\mathrm{a})} \mathrm{\kappa t}}
$$

The $\lambda$ and $\kappa$ parameters determined from the elicited opinions may be adjusted as new operation process data arrive on the investigated system failures.

Expressions (2) and (4) allow to estimate the probabilities of ICF type hazardous events in the determined time interval t. Another problem is estimation of the risk of consequences of these events, i.e. damage to or total loss of the ship and connected human, environmental and financial losses. This is a separate problem not discussed in this paper.

\section{DATA ACQUISITION}

The PS will be further treated as a system consisting of subsystems and those consisting of the sets of devices.

Experts are asked to treat the objects of their opinions as anthrop-technical systems, i.e. composed of technical and human (operators' functions) elements. They elicit their opinions in three layers in such a way that proper correlation is maintained between data of the system and data of the system components. In layer 0 opinions are expressed in numbers, in layers I and II - in linguistic terms. For layers I and II separate linguistic variables (LV) and linguistic term-sets (LT-S) have been defined (Piegat A. 1999).

Layer 0 - includes PS as a whole.

Estimated are the annual numbers of type ICF type failures of PS N(t) and the percentage share of time at sea $\kappa 100 \%$ in the time of expert's observation. 
Layer I - includes decomposition of PS to a subsystem level.

$+\mathrm{LV}=$ share of the number of subsystem failures in the number of type ICF failures of PS.

+ LT-S = A1-very small/none, B1-small, C1-medium, D1large, E1-very large.

Layer II - includes the decomposition of subsystems to the sets of devices (set of devices is a part of subsystem forming a certain functional entity whose catastrophic failure causes catastrophic failure of the subsystem - e.g. it may be a set of pumps of the cooling fresh water subsystem).

$\lambda \mathrm{LV}=$ share of the number of failures of the sets of devices in the number of catastrophic failures of the respective PS subsystem.

ᄉ LT-S = A2-very small/none, B2-small, C2-medium, D2large, E2-very large.

The structure of data acquisition procedure presented here implies a series form of the reliability structures of subsystems (layer I) and sets of devices (layer II). Elements of those structures should be so defined that their catastrophic failures cause equally catastrophic failures of the PS system and subsystem respectively. The division into subsystems and sets of devices should be complete and disjunctive.

The data acquisition procedure presented here takes into account the expert potential abilities. It seems that their knowledge should be more precise in the case of a large operationally important system, as the PS is, and less precise as regards individual components of the system.

\section{ALGORITHM OF EXPERT OPINION PROCESSING}

In layer 0 the experts elicit annual numbers of the ICF type failures, which, in their opinion, might have occurred during 1 year in the investigated PS type:

$$
\mathrm{N}_{\mathrm{j}}(\mathrm{t}) \mathrm{j}=1,2, \ldots, \mathrm{J}
$$

and shares of the time at sea in the calendar time of ship operation:

$$
\kappa_{\mathrm{j}} 100 \% \mathrm{j}=1,2, \ldots, \mathrm{J}
$$

where:

$\mathrm{j}-$ experts index

$\mathrm{J}-$ number of experts.

These sets of values are subjected to selection due to possible errors made by the experts. In this case a statistical test of the distance from the mean value may be useful, as in general we do not have at our disposal any objective field data to be treated as a reference set.

If the data lot size after selection appears insufficient, it may be increased by the bootstrap method (Efron \& Tibshirani 1993).

From the data (5) and (6), parameters $\lambda^{(a)}$ and $\kappa$ of expression (2) and (4) are determined. Number of opinions J may be changed after the selection.

In layer I experts elicit the linguistic values of subsystem shares in the number of ICF type failures of the investigated PS type (they choose LV value from the $\{\mathrm{A} 1, \mathrm{~B} 1, \mathrm{C} 1, \mathrm{D} 1, \mathrm{E} 1\}$ set). The data are subjected to selection.

The elicited data with linguistic values are compared in pairs - estimation of each subsystem is compared with estimation of each subsystem. The linguistic estimations are transformed into numerical estimations according to the following pattern:

$\mathrm{LT}-\mathrm{S}=\mathrm{B} 1 \Rightarrow 2$

$\mathrm{LT}-\mathrm{S}=\mathrm{C} 1 \Rightarrow 3$

$\mathrm{LT}-\mathrm{S}=\mathrm{D} 1 \Rightarrow 4$

$\mathrm{LT}-\mathrm{S}=\mathrm{E} 1 \Rightarrow 5$

Numerical estimates of each subsystem are subtracted from estimates of each subsystem. In this way the difference values are obtained, which may have the following values: $-4,-3,-2,-1,0,1,2,3,4$. Those differences are transferred into preference estimates (as given in Tab. 1) in accordance with the following pattern:

$4 \Rightarrow 9$, absolute preference

$3 \Rightarrow 7$, clear preference

$2 \Rightarrow 5$, significant preference

$1 \Rightarrow 3$, weak preference

$0 \Rightarrow 1$, equivalence

$-1 \Rightarrow 1 / 3$, inverse of weak preference

$-2 \Rightarrow 1 / 5$, inverse of significant preference

$-3 \Rightarrow 1 / 7$, inverse of clear preference

$-4 \Rightarrow 1 / 9$, inverse of absolute preference.

From these differences, by the pair comparison method, a matrix of estimates is constructed. The estimates depend on the „distance" of the linguistic values LT-S of a given variable LV. For instance, preference A1 in relation to E1 has the value 9 assigned, in relation to $\mathrm{D} 1$ a value 7 , in relation to $\mathrm{C} 1$ a value 5. In relation to $\mathrm{B} 1$ a value 3 and in relation to $\mathrm{A} 1$ a value 1 . The inverses of those preferences have the values, respectively: $1 / 9,1 / 7,1 / 5,1 / 3$ and 1 . The matrix of estimates is approximated by the matrix of weight quotients of the sought arrangement. The recommended processing method is the logarithmic least squares method. The result is a vector of normalized arrangements of the subsystem shares (Saaty 1980, Kwiesielewicz 2002) ${ }^{3}$ :

$$
\mathbf{p}=\left[\mathrm{p}_{1}, \mathrm{p}_{2}, \ldots, \mathrm{p}_{\mathrm{i}}, \ldots, \mathrm{p}_{\mathrm{I}}\right]
$$

where:

$\mathrm{p}_{1}$ - share of the $\mathrm{i}$-th subsystem as a cause of an ICF type PS failure

I - number of subsystems.

Now we can determine in a simple way the intensity functions of individual subsystems arising from catastrophic failures:

$$
\lambda_{i}^{(a)}=\lambda^{(a)} p_{i}, i=1,2, \ldots, I
$$

Tab. 1. Expert preference estimates acc. to Saaty (1980)

\begin{tabular}{|c|c|}
\hline Estimate & Preference \\
\hline 1 & Equivalence \\
\hline 3 & Weak preference \\
\hline 5 & Significant preference \\
\hline 7 & Strong preference \\
\hline 9 & Absolute preference \\
\hline $\begin{array}{c}\text { Inverse of the } \\
\text { above numbers }\end{array}$ & Inverse of the above described preference \\
\hline
\end{tabular}

In layer II experts elicit the linguistic values of subset shares in the number of catastrophic subsystem failures (they choose $\mathrm{LV}$ value from the $\{\mathrm{A} 2, \mathrm{~B} 2, \mathrm{C} 2, \mathrm{D} 2, \mathrm{E} 2\}$ set). As in the case of subsystems, the expert opinions are processed to the form of normalized vectors of the arrangements of set shares: 
$\mathbf{p}_{\mathbf{i}}=\left[\mathrm{p}_{\mathrm{i} 1}, \mathrm{p}_{\mathrm{i} 2}, \ldots, \mathrm{p}_{\mathrm{ik}}, \ldots, \mathrm{p}_{\mathrm{iK}}\right] ; \mathrm{i}=1,2, \ldots, \mathrm{I} ; \mathrm{k}=1,2, \ldots, \mathrm{K}(9)$

where:

$\mathbf{p}_{\mathbf{i}}-$ vector of the shares of $\mathrm{i}$-th subsystem sets as causes of catastrophic failures of that subsystem

$p_{i k}$ - share of the $k$-th set of $i$-th subsystem

$\mathrm{K}$ - number of sets in a given subsystem.

Then, the intensity functions of sets contained in individual subsystems arising from catastrophic failures are determined:

$$
\lambda_{\mathrm{ik}}^{(\mathrm{a})}=\lambda_{\mathrm{i}}^{(\mathrm{a})} \mathrm{p}_{\mathrm{ik}} ; \mathrm{i}=1,2, \ldots, \mathrm{I} ; \mathrm{k}=1,2, \ldots, \mathrm{K}
$$

\section{EXAMPLE}

The example discusses investigation of a PS consisting of a low speed piston combustion engine driving a fix pitch propeller, installed in a container carrier ship. Experts were marine engineers with long experience (50 ship officers with chief engineer or second engineer diploma). Special questionnaire was prepared for them containing definition of the investigated object, schematic diagrams of subsystems and sets, precisely formulated questions and tables for answers. It was clearly stated in the questionnaire that an ICF type failure may be caused by a device failures or by a crew actions.

Out of 50 opinions elicited by experts, 3 were estimated as very unlikely ( 2 elicited numbers of the ICF events in a year were extremely underestimated and one was overestimated). They were eliminated and the remaining 47 opinions were further processed.

Figs. 1 and 2 present statistical estimates of the expert opinion data (5) and (6).

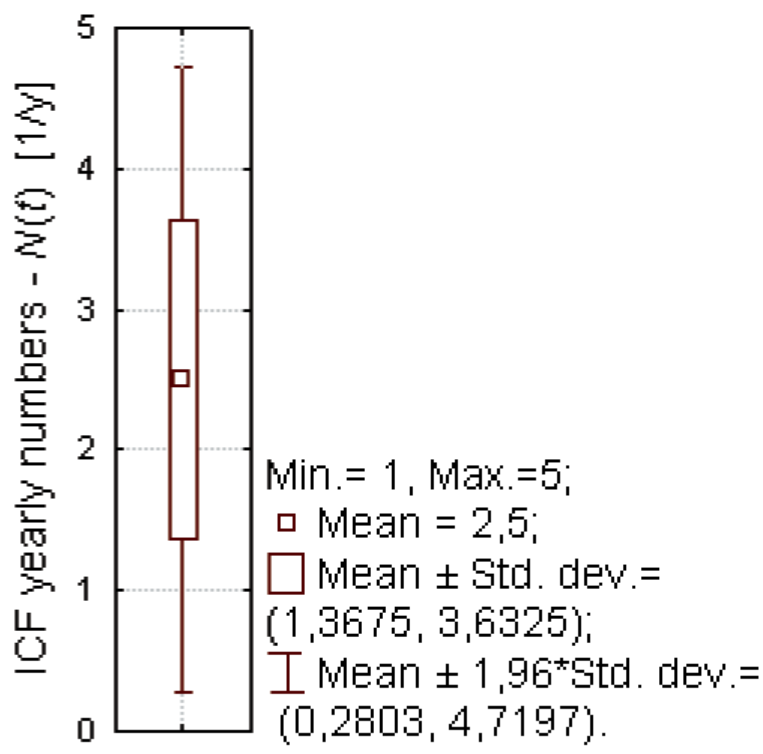

Fig. 1. Box and whiskers plot of ICF yearly numbers

Tab. 2 contains averaged basic data elicited by 47 experts in relation to the PS as a whole and the model parameters of ICF type event probability [equation (2)] determined from these data.

From the Tab. 2 data the probabilities of determined numbers of ICF type event occurrences in 1 year were calculated. Fig. 3 diagram presents results of those calculations. The numbers of probable ICF events in 1 year are equal $1,2, \ldots, 5$. The maximum probability is 0.2565 , which stands for 2 ICF type events during 1 year, and the probability that such event will not occur amounts to 0.0821 .

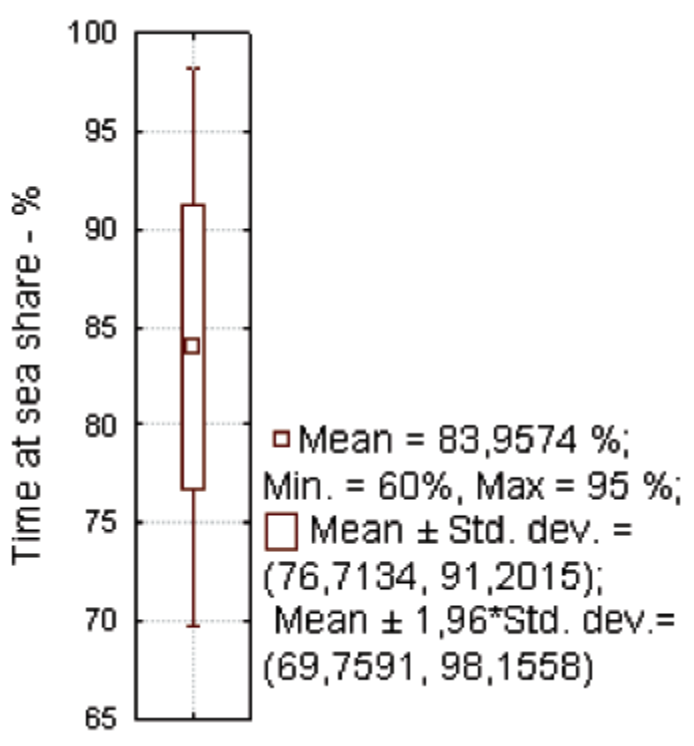

Fig. 2. Box and whiskers plot of time at sea share

Tab. 2. Basic results of propulsion system investigation

\begin{tabular}{|c|c|}
\hline $\begin{array}{c}\text { Averaged } \\
\text { expert elicited } \\
\text { data }\end{array}$ & $\overline{\mathrm{N}}(1 \mathrm{y})=2.5$ \\
$\sigma[\mathrm{N}(1 \mathrm{y})]=1.1325$ \\
$\bar{\kappa} 100=83.95745$ \\
$\sigma[\kappa 100]=7.24406$ \\
\hline $\begin{array}{c}\text { Risk model } \\
\text { parameters }\end{array}$ & $\sum_{1}^{47} \mathrm{t}=411720 \mathrm{~h}$ \\
& $\lambda^{(\mathrm{a})}=3.39922 \mathrm{E}-04 \mathrm{~K} / \mathrm{h}$ \\
\hline
\end{tabular}

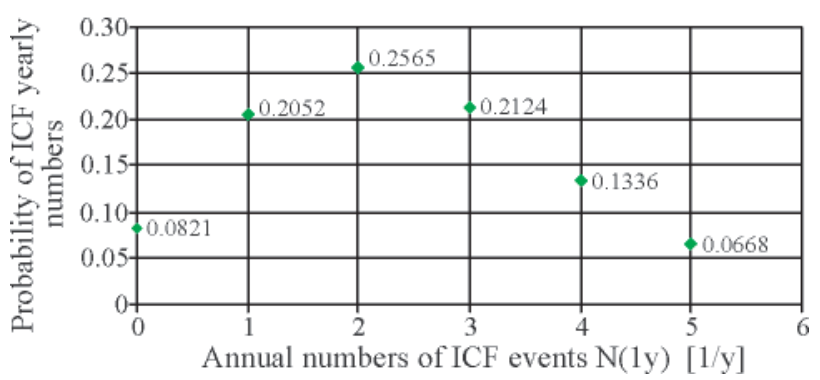

Fig. 3. Disribution of ICF event numbers ' probability

Tab. 3 contains the subsystem intensity function (ROCOF) data calculated from equation (8). The main PS risk "participants" are main engine and the electrical subsystem and the least meaningful is the propeller with shaft line. This is in agreement with the experience of each shipbuilder and marine engineer.

Tab. 4 contains the fuel supply subsystem intensity function (ROCOF) data calculated from equation (10).

Tab. 3. Intensity functions of the subsystems

\begin{tabular}{|c|c|c|c|}
\hline No & Subsystem & $\mathbf{p}_{\mathbf{i}}$ & $\boldsymbol{\lambda}^{\text {(a) }} \mathbf{1 0}^{\mathbf{- 5}}$ \\
\hline $\mathbf{1}$ & Fuel oil subsystem & 0.1330 & 4.5203 \\
\hline $\mathbf{2}$ & Sea water cooling subsystem & 0.0437 & 1.4852 \\
\hline $\mathbf{3}$ & $\begin{array}{c}\text { Low temperature fresh water } \\
\text { cooling subsystem }\end{array}$ & 0.0395 & 1.3426 \\
\hline
\end{tabular}




\begin{tabular}{|c|c|c|c|}
\hline $\mathbf{N o}$ & Subsystem & $\mathbf{p}_{\mathbf{i}}$ & $\boldsymbol{\lambda}^{\text {(a) }} \mathbf{1 0}$ \\
\hline $\mathbf{4}$ & $\begin{array}{c}\text { High temperature fresh water } \\
\text { cooling subsystem }\end{array}$ & 0.0620 & 2.1074 \\
\hline $\mathbf{5}$ & Starting air subsystem & 0.0853 & 2.9006 \\
\hline $\mathbf{6}$ & Lubrication oil subsystem & 0.0687 & 2.3352 \\
\hline $\mathbf{7}$ & Cylinder lubrication oil & 0.0446 & 1.5147 \\
\hline $\mathbf{8}$ & subsystem & 0.1876 & 6.3770 \\
\hline $\mathbf{9}$ & Electrical subsystem & 0.1987 & 6.7536 \\
\hline $\mathbf{1 0}$ & Main engine & 0.1122 & 3.8146 \\
\hline $\mathbf{1 1}$ & Propeller + shaft line & 0.0247 & 0.8410 \\
\hline
\end{tabular}

Tab. 4. Intensity functions of the fuel oil subsystem sets

\begin{tabular}{|c|c|c|c|}
\hline No & Set & $\mathbf{p}_{\mathbf{i k}}$ & $\lambda_{\mathbf{i k}}^{(\mathbf{a})} \mathbf{1 0}^{-\mathbf{6}}$ \\
\hline $\mathbf{1}$ & Fuel oil service tanks & 0.0488 & 2.2062 \\
\hline $\mathbf{2}$ & Fuel oil supply pumps & 0.1672 & 7.5572 \\
\hline $\mathbf{3}$ & Fuel oil circulating pumps & 0.1833 & 8.2840 \\
\hline $\mathbf{4}$ & Fuel oil heaters. & 0.0944 & 4.2666 \\
\hline $\mathbf{5}$ & Filters & 0.1540 & 6.9599 \\
\hline $\mathbf{6}$ & Viscosity control arrangement & 0.2352 & 10.6323 \\
\hline $\mathbf{7}$ & $\begin{array}{c}\text { Piping + heating up steam } \\
\text { arrangement }\end{array}$ & 0.1172 & 5.2965 \\
\hline
\end{tabular}

\section{SUMMARY}

The paper presents a method of subjective estimation of the hazard connected with losing by a seagoing ship of the propulsion function capability. The estimation is based on opinions elicited by experts - experienced marine engineers. The method is illustrated by an example of such estimation in the case of a propulsion system with a low speed diesel engine and a fix pitch propeller installed in a container carrier.
The given in section 6 do not raise any objections. The author does not have at his disposal sufficient objective data to evaluate precisely the adequacy of those data. It has to be taken into account that results of a subjective character may, by virtue of the fact, bear greater errors than the objective results achieved from investigations in real operational conditions.

T The presented method may be used in the procedures of the ship propulsion risk prediction. It allows to investigate the impact of the PS system component reliability on the probability values of ICF type event. It may also be used with other types of ship systems and not only to ship systems, particularly in the situations of hazardous event probability estimations with insufficient objective data at hand.

\section{BIBLIOGRAPHY}

1. Gniedienko B.V., Bielajev J.K., Soloviev A.D.: Mathematical Methods in Reliability Theory (in Polish). Warszawa: Wydawnictwa Naukowo-Techniczne, 1965

2. Saaty T.L.: The Analytical Hierarchy Process. New York et al: McGraw-Hill, 1980

3. Kwiesielewicz M.: Analytical Hierarchy Decision Process. Fuzzy and Non-fuzzy Paired Comparison (in Polish). Warszawa: Instytut Badań Systemowych PAN, 2002

4. Modarres M., Kaminskiy M., Krivtsov.: Reliability Engineering and Risk Analysis. New York, Basel: Marcel Dekker, Inc., 1999

5. Piegat A.: Fuzzy Modeling and Control (in Polish). Warszawa: Akademicka Oficyna Wydawnicza EXIT, 1999

6. IMO. Resolution A.849(20).: Code for the investigation of marine casualties and incidents. London, 1997

7. Roland H. E., Moriarty B.:. System Safety Engineering and Management. John Wiley \& Sons, Inc. New York, Chichester, Brisbane, Toronto, Singapore, 1990.

\section{CONTACT WITH THE AUTHORS}

Alfred Brandowski, Prof. Faculty of Marine Engineering Department of Engineering Sciences, Gdynia Maritime University Morska 83

81-225 Gdynia, POLAND e-mail: abrand@am.gdynia.pl 